\title{
Making the Application of E-Marketplace with the Use of Virtual Account on Company
}

\author{
Hermawan Heriyanto \\ Informatics Engineering \\ Petra Christian University \\ Surabaya, Indonesia
}

\author{
Alexander Setiawan \\ Informatics Engineering \\ Petra Christian University \\ Surabaya, Indonesia
}

\author{
Adi Wibowo \\ Informatics Engineering \\ Petra Christian University \\ Surabaya, Indonesia
}

\begin{abstract}
Indonesia is home to various marketplace sites such as Lazada, Bukalapak, and Tokopedia. The tight competition between marketplace sites encourages businesspeople to innovate in creating a new marketplace that is safe, comfortable and innovative. One innovative that can be done is of a system of cooperation with suppliers. Based on this background company trying to make an online application marketplace with a system of cooperation in a lease, or a combination of the rental fee and the fee. This application is expected to create security in the process of buying and selling as well as it can compete with the existing marketplace. The whole process of the transaction, the complaint and the ad would also be integrated into the system, thereby reducing the risk of human error. Overall the application complies with the requirements of the company. In addition to getting the ease in getting customers, suppliers also feel the ease and safety in working in company
\end{abstract}

Keywords: Marketplace, Rent, Fee, System Cooperation

\section{INTRODUCTION}

Indonesia is home to various marketplace sites such as Lazada, Bukalapak, and Tokopedia. These Marketplace offers an advantages to maintain the position in order to remain competitive with competitors. For example one of the benefits of cooperation in Tokopedia is registration for free. These advantages encourages businesspeople to innovate in creating a new marketplace to compete with the marketplace that has been stood.

One of the innovative in establishing new marketplace is to create a different system of cooperation with suppliers. The system of cooperation may take the form of rent, fees and a combination of rental and fees.

The company that wants to create a whole new marketplace with a category of goods is a bag. In this case, company plan to create an online marketplace of applications are supported by the implementation of the joint account system and transaction fee. This application is expected to reduce the sense of insecurity customers and capable of competing with the marketplace that have stood because can facilitate collaboration with various suppliers of bags.

\section{BASIC THEORY}

\subsection{E-Marketplace}

E-Marketplace is a virtual market where buyers and sellers meet and conduct various types of transactions. Here the process of exchange of goods, services, money or information. Virtual marketplace connecting sellers and buyers via the Internet. The process of exchange of services and goods in the virtual world is defined as e-commerce. There are 5 things that infrastructure to support e-commerce, namely people, public policy, marketing and advertising, support services, and business partnerships. [4]

E-commerce also has several characteristics, namely: the Internet is a media intermediary in the process of buying and selling, the process of the transaction and the exchange of goods, information and services. Besides e-commerce also has several types, namely: Business to Business (B2B), Business to Consumer (B2C), Consumer to Consumer (C2C), Consumer to Business (C2B) and Collaborative Commerce.
Marketplace, including the type of Business to Business (B2B). This is because the transactions that occur in the marketplace involves the relationship between the seller and not directly in the hands of the end (end-user) / customer. [2]

\section{SYSTEM DESIGN}

\subsection{Requiremnt Analysis}

Reasons doneonline marketplace creation of applications in this research is to create an innovative online marketplace with the three types of application of the system of cooperation with PHP and CSS Design [1][3]. Rental system facilitates cost provider of goods where payment is always the same regardless of the number of sales that occurred. Fee system of cooperation in which the provider of goods will pay some persetase goods sold and a combination of rental and fee system where the system will help suppliers in making the transition from the system to the rental fee.

\subsection{System Analysis}

In this research, the application program that is used to apply 3 system of cooperation with suppliers. The application of the registration process starts from supplier to sales calculation process that has been accomplished.

\subsubsection{Supplier Registration}

On the supplier registration process, the application data to be recorded by the system supplier and activation email sent to the supplier. Supplier account activation process begins with checking the data stored on the system and activate the account if achieved compliance. Explanation of supplier registration process can be seen in Figure 1 


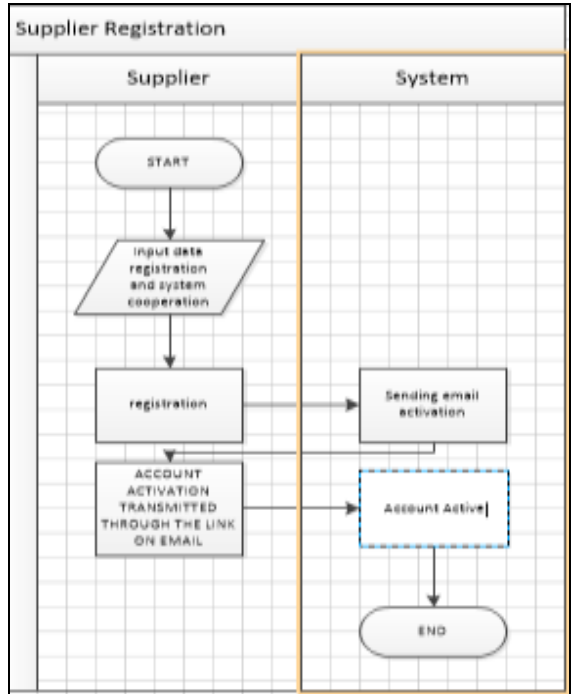

Figure 1 Supplier Registration

\subsubsection{Sales of Goods}

\subsubsection{Ordering Goods}

In the process of ordering goods, the data of goods ordered and the shipping costs will be recorded and the recording system will provide confirmation of an order made by the customer. Explanation of the process of ordering goods can be seen in Figure 2.

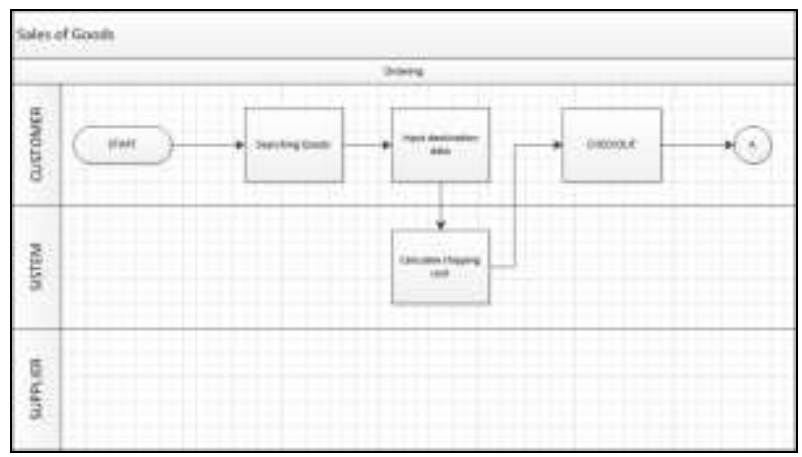

Figure 2 Ordering Items

\subsubsection{Customer Payment}

In the process of payment, payment data will be recorded and admin company will provide confirmation of payment to the customer. After admin confirmation, the system will provide notification to the supplier that the booking has been paid by the customer. Explanation customer payment process can be seen in Figure 3

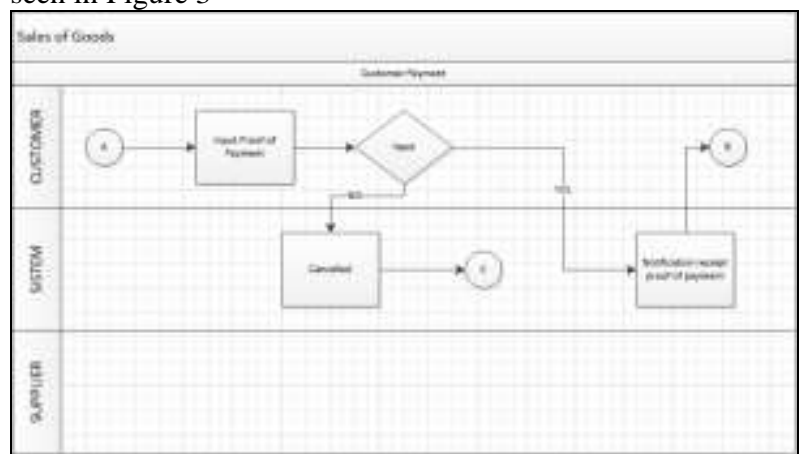

Figure 3 Customer Payment

\subsubsection{Shipping}

In the shipping process, shipping of data will be stored and notification every stage of the delivery of goods will be accepted by the customer. Explanation of the shipping process can be seen in Figure 4.

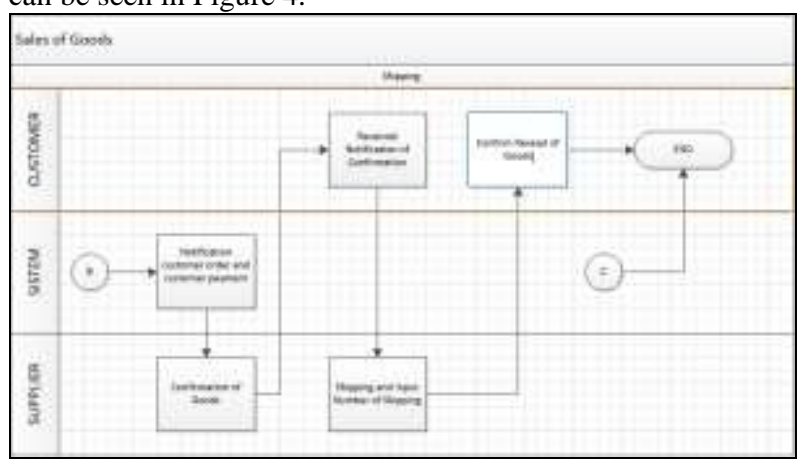

Figure 4 Shipping

3.2.3 Calculation of sales that have been completed In this process, a notification will be sent details of the sale have been calculated for a range of dates specified. Furthermore, the supplier must confirm that the details have been received and true as in Figure 5.

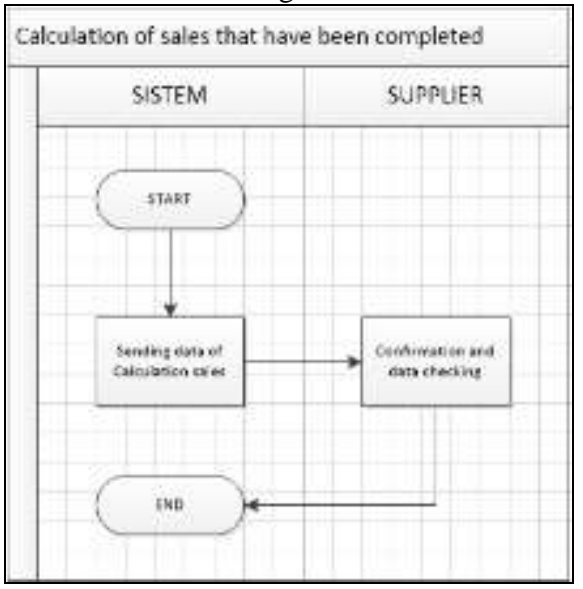

Figure 5 Calculation of Sales

\section{APPLICATION IMPLEMENTATION} 4.1 Implementation of Supplier

\section{Registration}

In this application, the supplier can register your account by completing the registration form account as shown in Figure 6. For example, email is filled with elf.buster@gmail.com, the password is also required, the name Heri stocked shop, filled phone number 082231417888, address filled jl.malang 2, select the province of East Java, select the town of Kediri, a system of cooperation been rent and filing requests cooperation filled $\mathrm{Rp} 1,000,000$. 


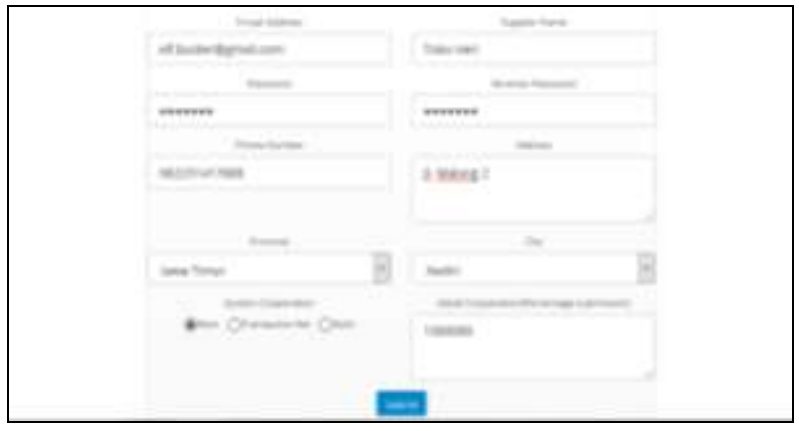

Figure 6 Supplier Registration

After filling and signing up is complete, the supplier will receive an email containing the account activation link to activate your account supplier but still can not be used because it must wait for approval as in Figure 7.

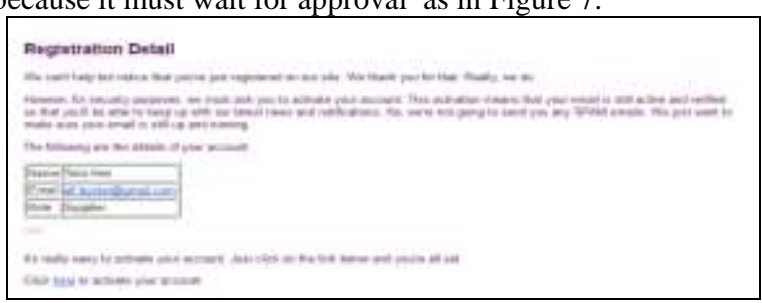

Figure 7 Email Activation

Once active, the company will contact the applicant and make determinations cooperation. Admin of the company can classify the supplier in accordance with the agreement as shown in Figure 8, and activate the account so that the supplier can use an account that has been registered in accordance with Figure 9.

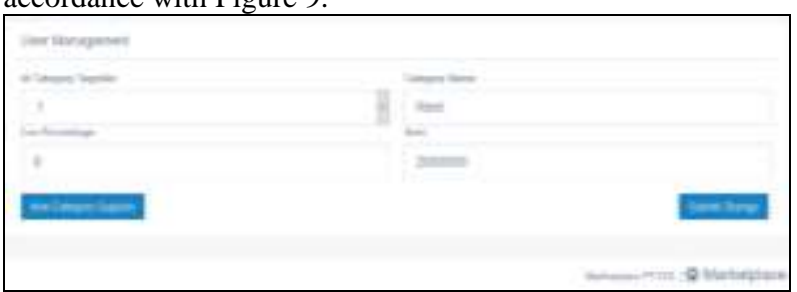

Figure 8 Classify Supplier Category

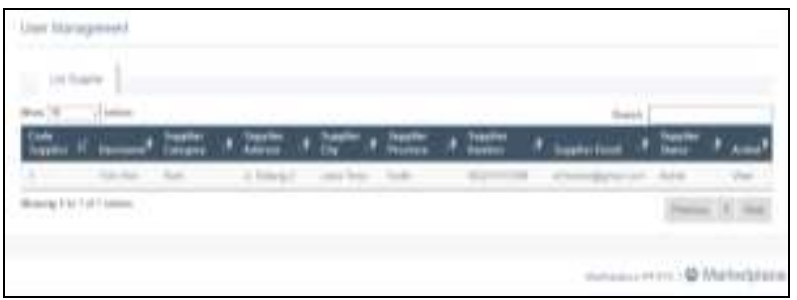

Figure 9 Activation Supplier Account

\subsection{Sales of Goods Implementation}

\subsubsection{Ordering}

Customers who visit the marketplace application is able to see a wide variety of goods sold as Figure 10 without the need to perform the login process

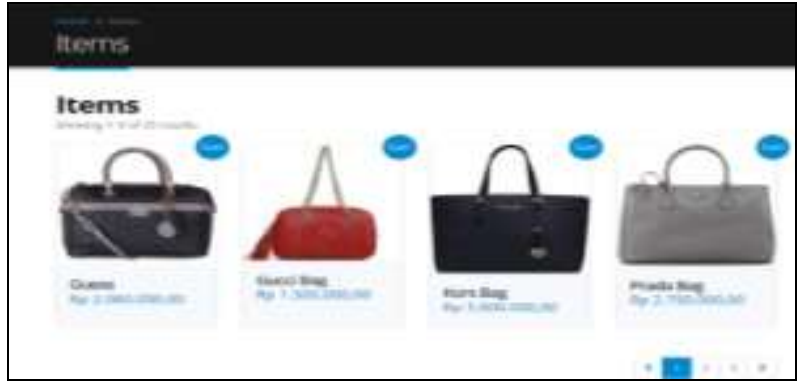

Figure 10 List of Items

However, if you want to order goods by including a shopping cart, login process needs to be done first. After entering all the items to be purchased on the shopping cart, the customer can see the suitability of ordering goods that do like Figure 11.

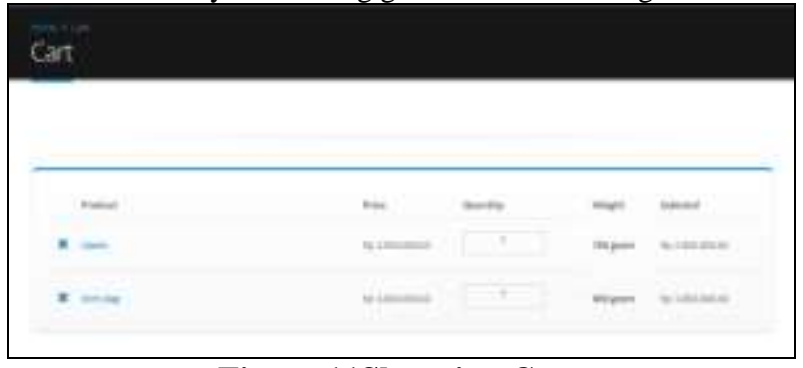

Figure 11Shopping Cart

The data required to be filled out completely and clearly so that the process of calculating the cost of shipping and delivery process runs smoothly. For example, for a field filled with Hermawan name, phone number field filled 08223141788 , the address field is filled with jl.malang 2, East Java provinces were selected field, field Kediri city selected. Upon completion of the complete data, by pressing the button updates the shipping cost shipping fees will be calculated as shown in Figure 12.

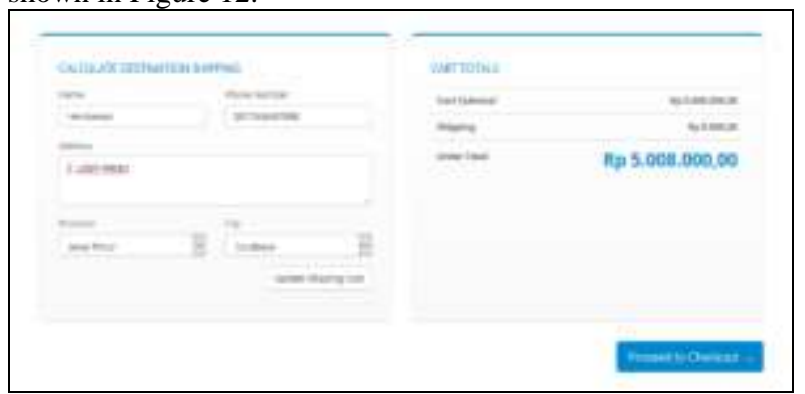

Figure 12 Destination and Shipping Data

After making the checkout process, the customer will get a notification purchases of goods as successful as in Figure 13

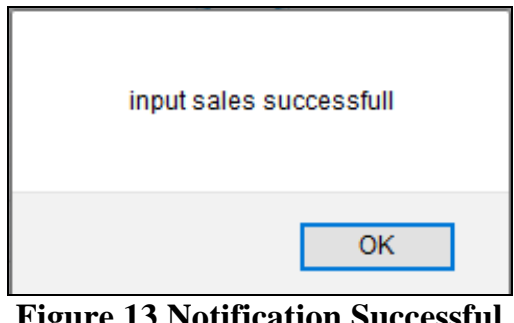

4.2.2 Customer Payment

Customers who have made the process of buying goods, can see the status of orders as in Figure 14 


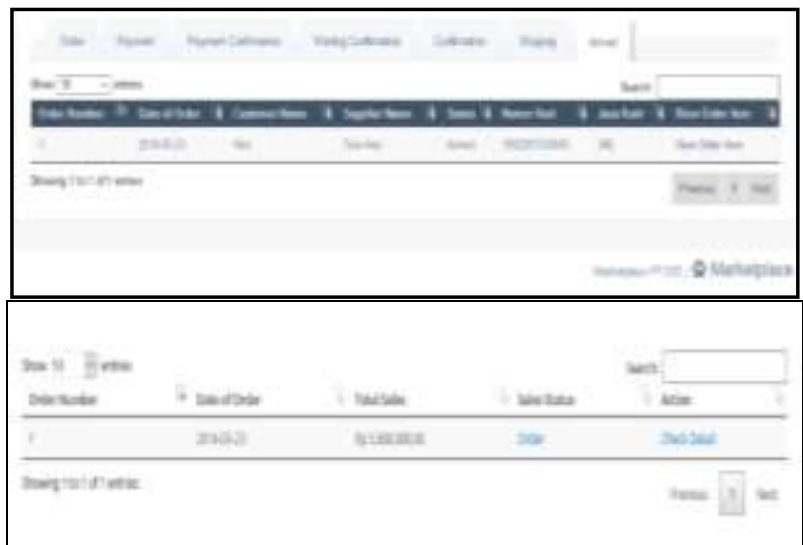

Figure 14 List of Sales

For customers who have not made the payment process, can make the payment process by the method of transfer and input the transfer of evidence as inFigure 15.

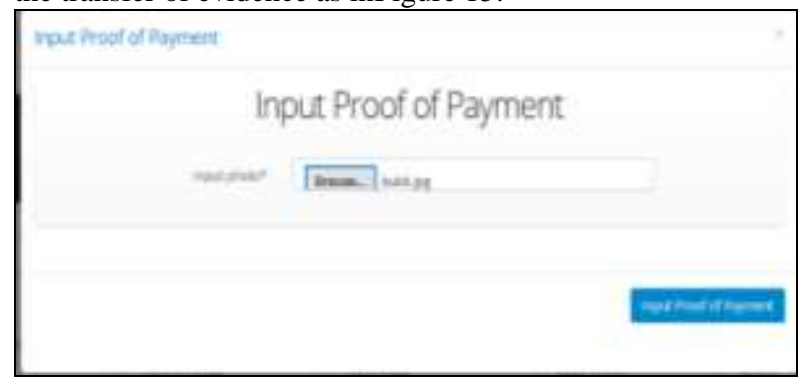

Figure 15 Input Proof of Payment

After making a payment, purchase status will change to payment as Figure 16 and then customer only waiting to see the goods delivery status likeFigure 17.

\begin{tabular}{|c|c|c|c|c|}
\hline \multicolumn{3}{|l|}{ 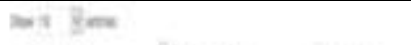 } & \multicolumn{2}{|c|}{ inn } \\
\hline mos & Thents & in wes & I laves & $1=$ \\
\hline 1 & mass & voman & $m$ & $=0 \times$ \\
\hline menixtm & & & & $\operatorname{mos} \mid 1]=$ \\
\hline
\end{tabular}

Figure 16 List of Payment Sales

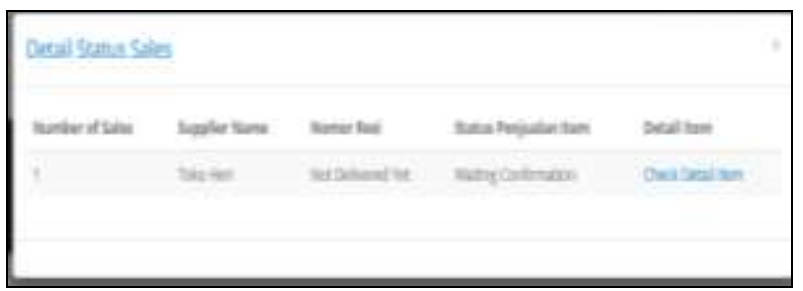

Figure 17 Status Delivery for Customer

Confirmation process customer payment can be made by admin company if the customer has done inputting proof of transfer by changing the status of payment into a payment confirmation as in Figure 18 and Figure 19.

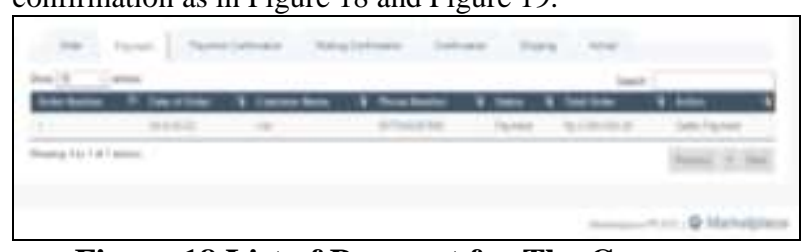

Figure 18 List of Payment for The Company

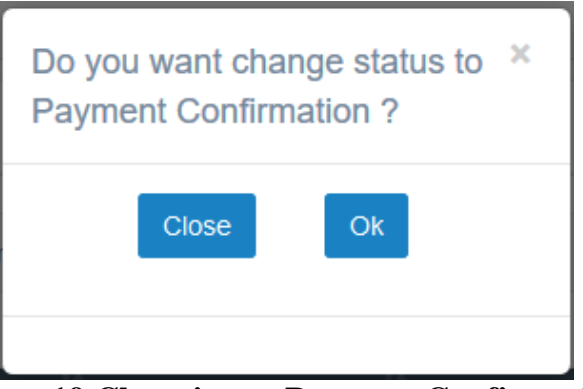

Figure 19 Changing to Payment Confirmation

\subsubsection{Shipping}

Sales have been confirmed payment by admin company will appear in parts of suppliers waiting confirmation as Figure 20.

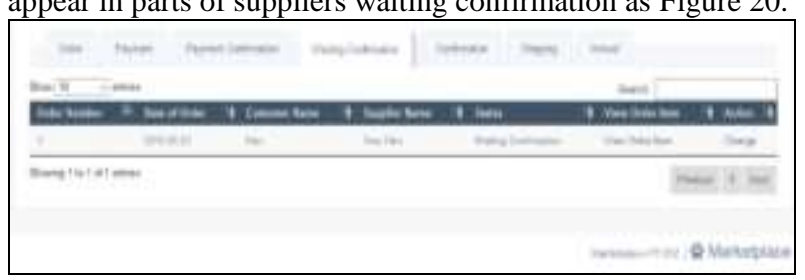

Figure 20 List of Waiting Confirmation Sales

Suppliers are required to confirm the booking made by the customer and confirmed the results will be displayed as in Figure 21.

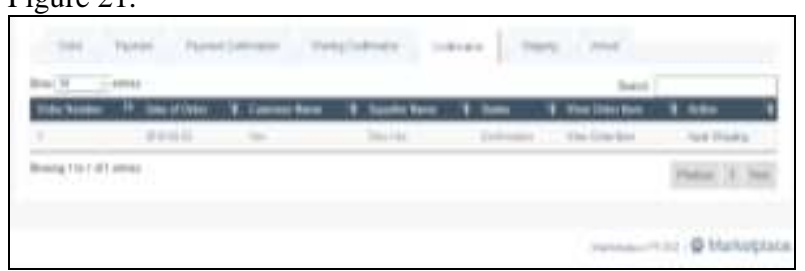

Figure 21 List of Confirmation Sales

Information will also be given confirmation to the customer such as Figure 22.

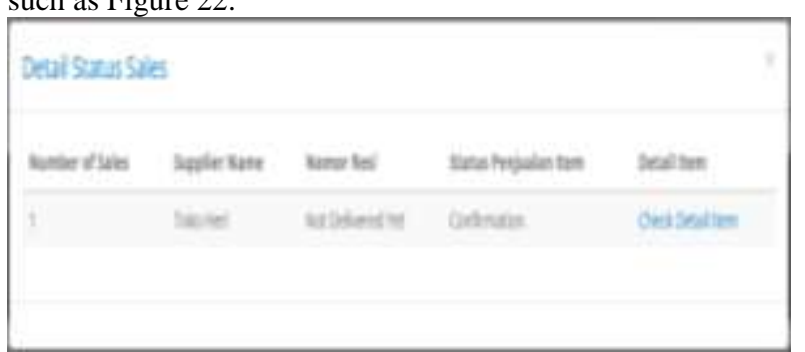

Figure 22 Information about Confirmation for Customer

The next item is ready to be delivered by courier JNE and the supplier will perform a data inputting shipping information such as Figure 23. 


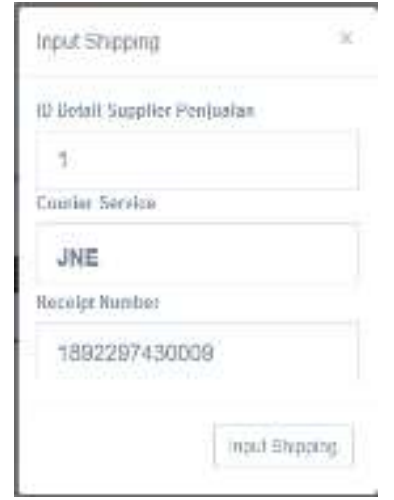

Figure 23 Input Data Shipping

Information delivery with shipping details will also be given to the customer as Figure 24.

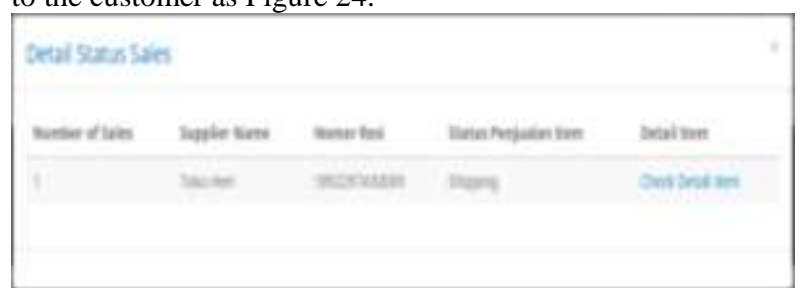

Figure 24 Information Shipping for Customer

If the goods have arrived at the destination, the supplier will change the status of the sale be arrived like Figure 25 and Figure 26

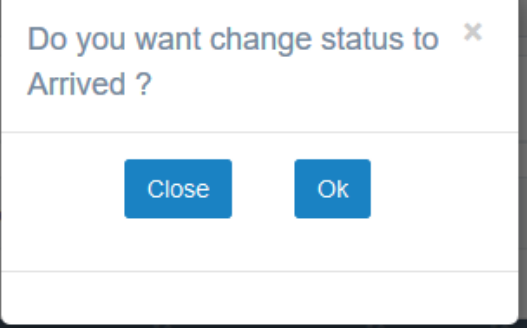

Figure 25 Changing Status to Arrive

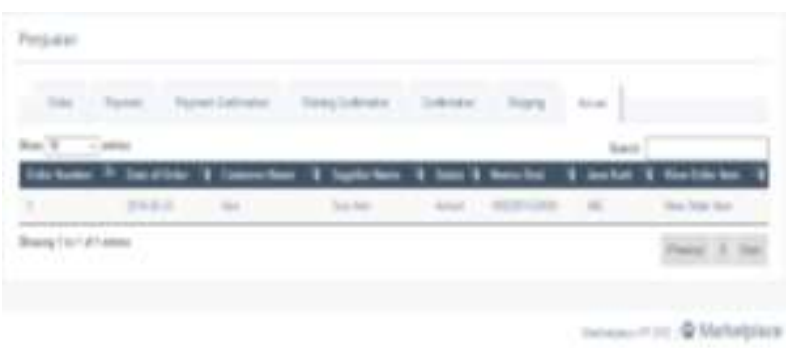

Figure 26 List of Sales Which Status is arrived

\subsection{Calculation of Sales}

The process of inputting payment begins by selecting a date range of sales calculation has been completed and has not been paid to the supplier. For example, from 1 May 2016 to 25 May 2016. Figure 27 is the result of the calculation details of sales during the specified time period.

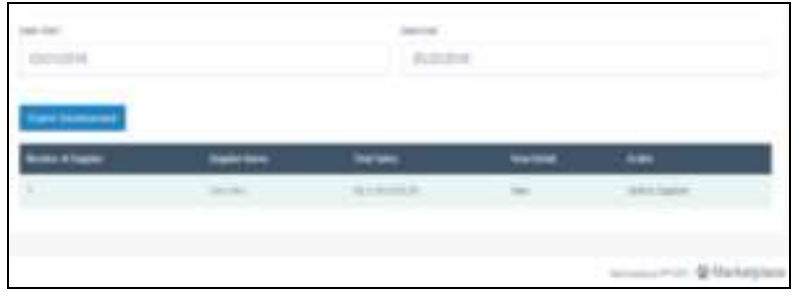

Figure 27 Calculation of Sales

Details of the sale can be sent like Figure 28. Details will be sent as an email to the supplier as in Figure 29.

\section{Do you want to sent detail of}

sales?

Figure 28 Sending Calculation of Sales

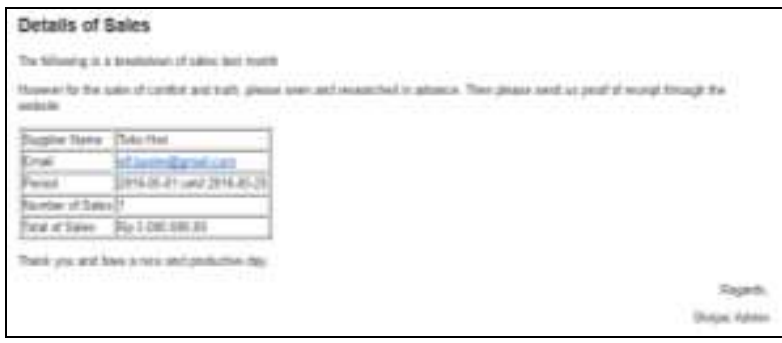

Figure 29 Email of Detail Calculation

\section{CONCLUSION}

Based on the test results we can conclude the following:

- Applications are made in accordance with the plan of the system to be applied to the company

- System of cooperation with suppliers is divided into three:

o Rent: the fee paid is always fixed every month

- The combination of rental and fees: fees paid by a percentage of the sales that have occurred coupled with the cost of rent per month

- Process of Sales divided into 3 phases, among others order, payment, and shipping

- The whole process of the transaction, the complaint and the advertisement will be integrated in the system, thereby reducing the risk of human error

\section{REFERENCES}

[1] Duckett, J. (2011). HTML \& CSS Design and Build Websites. Indiana: John Wiley \& Sons, Inc

[2] Laudon, K.C., dan Traver, C.G. (2013). E-commerce (9 $9^{\text {th }}$ ed). Pearson.

[3] Nixon, R. (2014). Learning PHP, MySQL, Javascript, CSS \& HTML5 (3rd ed). California: O'Reilly Media.

[4] Turban, E. (2012). Electronic Commerce ( $7^{\text {th }}$ ed). Pearson. 